\title{
Virtual screenings of the bioactive constituents of tea, prickly chaff, catechu, lemon, black pepper, and synthetic compounds with the main protease (Mpro) and human angiotensin-converting enzyme 2 (ACE 2) of SARS-CoV-2
}

Nazim Uddin Emon ${ }^{1,2^{*}}$ (D, Md. Munsur Alam ${ }^{1}$, Irin Akter $^{1}$, Saima Akhter ${ }^{1}$, Anjuman Ara Sneha ${ }^{1}$, Md. Irtiza ${ }^{1}$, Marufa Afroj ${ }^{1}$, Arifa Munni ${ }^{1}$, Masruba Hossen Chowdhury ${ }^{1}$ and Summiya Hossain ${ }^{1}$

\begin{abstract}
Background: COVID-19 has mutation capability, and there are no specific drug therapies that are available to fight or inhibit the proteins of this virus. The present study aims to investigate the binding affinity of the bioactive and synthetic compounds with the main protease (Mpro) enzymes and angiotensin-converting enzyme 2 (ACE 2) by computational approach. PASS prediction, pharmacokinetics, and toxicological properties prediction studies were performed through the Google PASS prediction and Swiss ADME/T website. Besides, molecular docking studies were accomplished by BIOVIA Discovery Studio 2020, UCSF Chimera, and PyRx autodock vina.

Results: The docking scores were inferred and the selected compounds showed results varying from -3.2 to -9.8 ( $\mathrm{kcal} / \mathrm{mol}$ ). Theaflavin scored the highest docking score to the 5REB, 6VW1, and $1 \mathrm{R} 42$ enzymes and showed the binding affinity as $-6.3 \mathrm{kcal} / \mathrm{mol},-9.8 \mathrm{kcal} / \mathrm{mol}$, and $-8.6 \mathrm{kcal} / \mathrm{mol}$, respectively. Again, kaempferol showed the best binding affinity to the 7BQY $(-7.1 \mathrm{kcal} / \mathrm{mol})$ and $6 \mathrm{Y} 2 \mathrm{FB}(-6.6 \mathrm{kcal} / \mathrm{mol})$ enzymes. All the chemical constituents showed better probability in action in pass prediction analysis. Besides, no ligands (except theaflavin) have any conflict with Lipinski's rules of five, which authorized the drug probability of these ligands.
\end{abstract}

Conclusion: Therefore, the selected compounds could be considered a potential herbal treatment source against SARS-COV-2.

Keywords: SARS-CoV-2, Theaflavin, Kaempferol, Drug targets, Molecular docking

\footnotetext{
* Correspondence: nazim7emon@gmail.com

'Department of Pharmacy, International Islamic University Chittagong, Chittagong 4318, Bangladesh

${ }^{2}$ Department of Public Health, School of Science and Technology, Bangladesh Open University, Gazipur 1705, Bangladesh
}

\section{Springer Open}

(c) The Author(s). 2021 Open Access This article is licensed under a Creative Commons Attribution 4.0 International License, which permits use, sharing, adaptation, distribution and reproduction in any medium or format, as long as you give appropriate credit to the original author(s) and the source, provide a link to the Creative Commons licence, and indicate if changes were made. The images or other third party material in this article are included in the article's Creative Commons licence, unless indicated otherwise in a credit line to the material. If material is not included in the article's Creative Commons licence and your intended use is not permitted by statutory regulation or exceeds the permitted use, you will need to obtain permission directly from the copyright holder. To view a copy of this licence, visit http://creativecommons.org/licenses/by/4.0/. 


\section{Background}

According to the WHO (World Health Organization), SARS-CoV-2 is now a pandemic crisis. It first appeared in the Wuhan province of China on 31 December 2019, and spread rapidly in the different parts of the world. Till 30 April 2021, there are 151,837,341 confirmed cases of 2019-nCoV infection, with 3,188,507 deaths found around the globe. The causative agent was identified from throat swab samples conducted by the Chinese Center for Disease Control and Prevention (CCDC) on 7 January 2020, and was subsequently named severe acute respiratory syndrome coronavirus-2 (SARS-CoV-2). The disease was named COVID-19 by the WHO [1]. Most SARS-CoV-2 infected patients are seen with symptoms such as dry cough, sore throat, and fever. The majority of cases have spontaneously resolved. However, some have developed various fatal complications, including organ failure, septic shock, pulmonary edema, severe pneumonia, and acute respiratory distress syndrome (ARDS) [2]. WHO declared the Chinese outbreak of COVID-19 to be a public health emergency of international concern, posing a high risk to countries with vulnerable health systems on 30 January 2020. The emergency committee has stated that the spread of COVID-19 may be interrupted by early detection, isolation, prompt treatment, and the implementation of a robust system to trace contacts [3].

Coronaviruses belong to the Coronaviridae family in the Nidovirales order. Corona contains crown-like spikes on the outer surface of the virus; thus, it was named coronavirus. Coronaviruses are minute in size $(65-125 \mathrm{~nm}$ in diameter) and contain a single-stranded RNA as a nucleic material, varying in length from 26 to $32 \mathrm{kbs}$. The subgroups of the coronaviruses family are alpha $(\alpha)$, beta $(\beta)$, gamma $(\gamma)$, and delta $(\delta)$ coronavirus [4]. SARS$\mathrm{CoV}-2$ fits the beta Coronavirus group [5]. COVID-19 (SARS-CoV-2) is composed of a spike protein (S), a membrane glycoprotein $(\mathrm{M})$, a hemagglutinin-esterase dimer (HE), an envelope protein (E), a nucleocapsid protein $(\mathrm{N})$, and an RNA. Spike glycoproteins are composed of two subunits (S1 and S2). Homotrimers of S proteins compose the spikes on the viral surface, guiding the link to host receptors $[5,6]$. Nucleocapsid protein $(\mathrm{N})$ binds in vitro to RNA and is heavily phosphorylated. N protein binds with the viral genome in a bead on a string type conformation, and $\mathrm{E}$ protein is found in small quantities within the virus, whereas the most abundant structural protein is the $M$ protein. This $M$ protein contains no signal sequence and is present in the virion as a dimer. $\mathrm{HE}$ is present in a subset of beta coronaviruses and binds sialic acids on surface glycoproteins [7]. Currently, no specific therapies for SARS-CoV-2 are available and investigations regarding the treatment of SARS-CoV-2 are lacking [8]. The viral genome also encodes nonstructural proteins which can be potential drug targets, including RNA-dependent RNA polymerase (RdRp), CoV main protease (3CLpro), and papain-like protease (PLpro) $[9,10]$.

SARS-CoV-2 (2019-nCoV) outbreak has become a global pandemic that has raised the concern of the scientific community to design and discover a definitive cure for this deadly virus. Research institutions are accelerating the discovery of vaccines and therapies for the SARSCoV-2. During the epidemic and pandemic outbreak of new viral pathogens, the conventional method of developing drugs and vaccination is not possible to control as it is a time-consuming process [11]. Consequently, the rapid approach based on in silico informatics has become very popular with recent advances in sequencing many pathogen genomes and protein sequence databases [12]. The steady rise of corona patient's with high mortality rate reinforces the urgency to produce a safe and efficient vaccine. The pharmacological effect of phytochemicals can be adequately explained by the use of virtual screening [13]. Methods and resources like computer-aided drug discovery (CADD) is also an effective way to design new pharmaceutical products. An effective molecular interaction through molecular docking can activate the native ligand to detect the threedimensional binding site of the enzyme and link to the relationship to the accompanying chemical compounds [14]. Taking the truth into account, a molecular docking study has been conducted to explain the phytoconstituents binding affinity with the five SARS-CoV-2 receptors. In this work, pass prediction, molecular docking, and pharmacokinetic regarding Lipinski's rules were checked for twelve ligands. To investigate the binding affinity of the ligands and SARS-CoV-2's receptors, the ligands were docked with the main protease and human angiotensin-converting enzyme 2 (ACE2) receptors of the SARS-CoV-2 virus owing to the best-characterized target among the SARS-CoV-2. Mainly, the binding interaction of caffeine, theaflavin, achyranthine, betaine, catechin, kaempferol, limonene, sabinene, piperine, pinene, favipiravir, and hydroxychloroquine (Fig. 1) against the proteins of COVID-19 have been screened by implying molecular docking simulations. The main protease (Mpro) (PDB ID: 7BQY, 6Y2F, 5REB) and human angiotensin-converting enzyme 2 (PDB ID: 6VW1, 1R42) were used as the target of the ligand interaction (Fig. 2). It was also previously reported that polyphenols, flavonoids, tannin, and derivate have fighting endeavors against many virions [15-17]. These components were chosen based on their therapeutic properties to bind with the SARS-CoV-2 proteins. Again, the mechanism of action of the established antiviral compounds like favipiravir and hydroxychloroquine is not fully uncovered. These compounds have the probable capacity to 


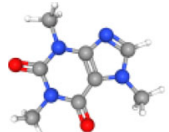

Caffeine

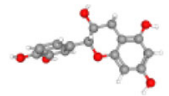

Catechin

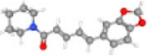

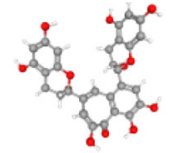

Theaflavin

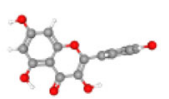

Kaempferol

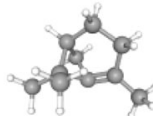

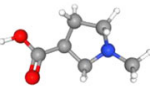

Achyranthine

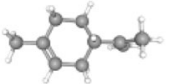

Limonene

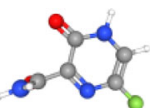

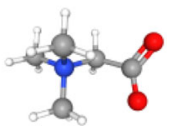

Betaine

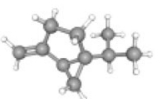

Sabinene

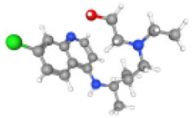

Piperine

Pinene

Favipiravir

Hydroxychloroquine

Fig. $13 \mathrm{D}$ chemical structure of selected ligands (caffeine, theaflavin, achyranthine, betaine, catechin, kaempferol, limonene, sabinene, piperine, pinene, favipiravir, hydroxychloroquine)

bind with the pockets of SARS-CoV-2; the study was encouraged to investigate the potential binding affinity of selected proteins with the previously selected ligands.

\section{Methods}

Bioactive constituents from black tea (Camellia sinensis L.) Tea (Camellia sinensis L.) is the second most used nonalcoholic beverage in the world after water. It has been consumed traditionally for about 5000 years. Black tea has 3 to $6 \%$ thearubigin, theaflavin, phenolics, and catechin. Thearubigins of tea are responsible for the deep red color of the tea, while theaflavins are accountable for the astringency and red/orange color of the tea. In black tea, the highest number of phenolic pigments in black tea is thearubigin. Theaflavins individually claimed to show antiviral potency [18]. Caffeine is one of the most popular natural stimulants which can be found in tea, cacao, and coffee [19]. A cup of black tea may contain 47 to $90 \mathrm{mg}$ of caffeine [20]. Caffeine seems to have a strong behavioral effect which is widely used as CNS stimulants. The phenolic component of tea was reported to have antiviral efficacy over adenovirus [21, 22].

\section{Bioactive constituents from prickly chaff (Achyranthes aspera L.)}

The herb is well known owing to have antiinflammatory, antidot (snake and scorpion bite), carminative, gastric, blood purifier, and diuretic effects. Decoction of the entire plant has been used in ascites, eczema, gastritis, skin rashes, and boils, and juice of the leaves often used to treat toothache [23]. The constituents of this pant are also reported to have antiviral properties [24, 25]. Though the entire plant ash has been used in herbal medicines for asthma, gaseous distention, urinary bladder stones, gastritis, and cough, honey ash can also be used to alleviate cough [26]. Achyranthine and betaine are abundantly found in A. aspera [27]. Betaine (BET) is known to protect the liver from toxicants as an indigenous drug. Betaine inhibits hepatitis $B$ viruses with the advantages of reducing resistance to interferon and lamivudine [28].

Bioactive constituents from catechu (Areca catechu Linn.) Areca nut (Areca catechu) is frequently used in betel quid, often consumed in betel and lime. Betel quid chewing seems to be extremely common, particularly in many countries in Southeast Asia [19]. Areca catechu is one of 54 recognized alkaloid-containing species in the Areca [29]. Several active ingredients such as arecatannin B1, procyanidins, and seed extracts have shown HIV enzyme inhibitory function. Alkaloids (0.5\%), phenol (31.1\%), fiber $(10.8 \%)$, fat (14.0\%), and polysaccharide (18.7\%) are key elements of the fruits of Areca catechu L. Alkaloids and polyphenols are the primary components in flower [30]. In Areca catechu, catechin and kaempferol were identified previously [31].

\section{Bioactive constituents from lemon (Citrus limon)}

Citrus limon is a flowing plant in the Rutaceae family [32]. The compounds of Citrus plants are the most common essential oil sources used in food products and medicines. Lemon seems to be very abundant in natural substances such as flavonoids, citric acid, minerals, ascorbic acid, and essential oils. Although modern citrus 


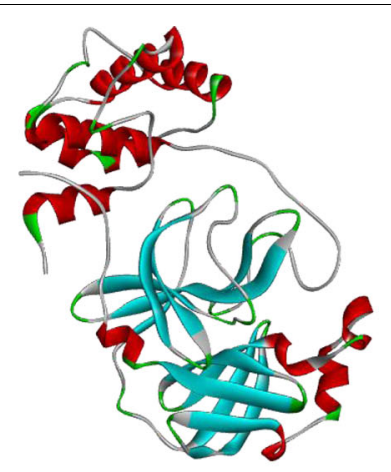

5REB

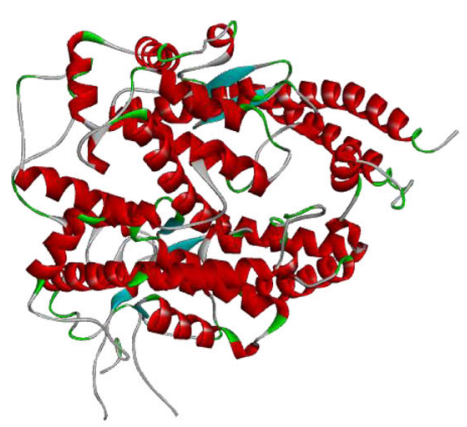

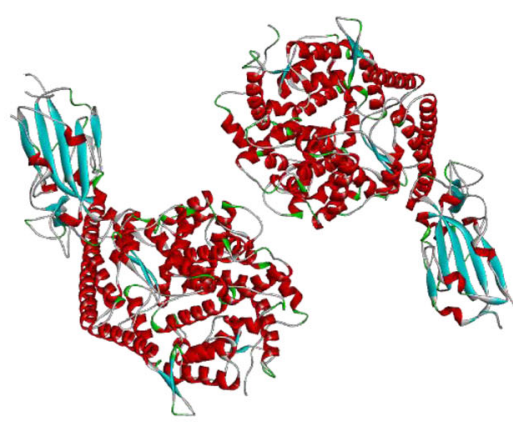

6VW1

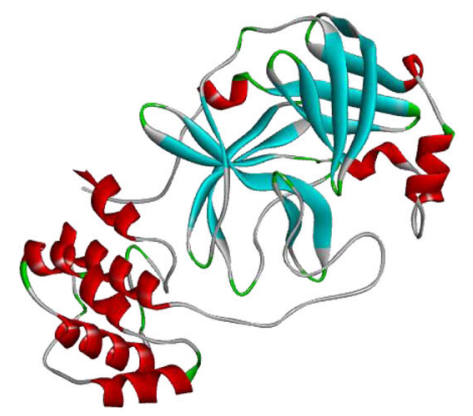

7BQY

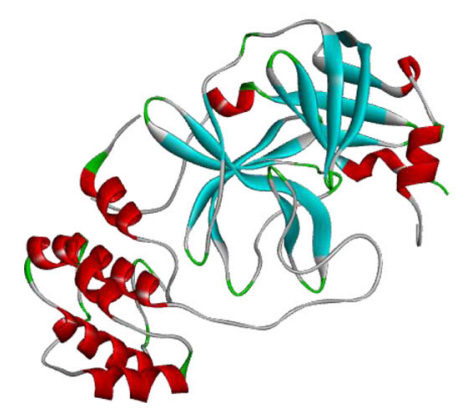

6Y2F

Fig. 2 3D structure of the pure receptors (5REB, 6VW1, 1R42, 7BQY, and 6Y2F) of SAR-CoV-2

cultivars were primarily designed for fresh use, their naturally drawn constituents, such as the flavonoids and phenolic compound, contributed to their use throughout food technology and pharmacological research [33]. Valuable academic publications concentrate on lemon fruit extract, juice, and essential oil, which are becoming much more comprehensive in pharmacological terms. These reports claim antiviral, antibacterial, anti-cancer, anti-inflammatory, and cardioprotective activities of lemon [34]. Sabinene (15.9\%) and limonene (31.5\%), are the major constituents of the citrus lemon [35]. Citrus flavonoids exert several pharmacological potentialities, including antiviral action [33].

Bioactive constituents from black pepper (Piper nigrum) Among the kitchen spices, pepper is one of the most commonly used spices around the globe. Pepper contains piperine and due to the pungent odor of the piperine, it has taken place as a kitchen spice. It is commonly used and widely permissible in various western medicinal systems, such as Unani and Ayurvedic [36]. Many illnesses, including antihypertensives [37, 38], antiplatelets, antioxidant, 
analgesic, antitumor, antithyroid, anticonvulsant [39], antibacterial, antidiarrheal, antidepressants, antispasmodic, immunomodulatory, anti-inflammatory, hepatoprotective, and antifungal have already been treated by this plant [37]. As a result, studies on its derivative synthesis, SAR modification and biological tests are underway and this has encouraged researchers to keep investigating it [40]. Piperine is also used in both conventional Chinese and Indian therapies. In influenza, nausea, rheumatoid arthritis, fever, and chills, piperine is used extensively [41]. Again, the previous studies reported that pinene has a strong suppression capacity for the herpes simplex virus [42]. It has been used for centuries to manufacture aromas and fragrances and demonstrates fungicidal activity. Various pharmacological activities, including natural insecticide, are attributed to pinenes. The studies showed strong antiviral potency of pinens against infectious bronchitis virus [42].

\section{Synthetic bioactive compounds (favipiravir and hydroxychloroquine)}

Favipiravir and hydroxychloroquine are under examination for the treatment of SARS-CoV-2, but the antiviral efficacy of these drugs is not apparent [43]. Favipiravir is a nucleoside precursor approved for the treatment of pandemic influenza in Japan [44]. However, its antiviral effect in patients with COVID-19 needs demanding data to support [45]. Hydroxychloroquine is a safer analog of chloroquine that has fewer concerns about drug-drug interactions [46]. Over one research, patients with combined treatment had lower viral loads in contrast to patients with a similar viral load-receiving hydroxychloroquine alone [47]. The suppression of cytokine release has been accelerated by downregulating the inflammatory effect of the drug [48]. Inhibition of cytokines reduces the elevation of chemotaxin of polymorphonuclear leucocytes in the lungs, which finally decreases the orientation of reactive oxygen [49].

\section{Protein targets}

Several approaches have been taken to establish $\mathrm{CoV}$ vaccines, most of which aim against spikes (S) or Sproteins, as they are the primary adjuvant to collapse antibodies. The main protease (M-pro) enzyme has been described as one of the primary goals for producing antiviral vaccines or drugs [50]. M-pro is present in the SARS-CoV-2's polyprotein ORF1ab and is important for virus replication. This protease participates in the degeneration of polyprotein [51]. Except for a residue (Ala285Thr), the association of the M-pro enzyme has been highly identified in the SARS-CoV virus [52]. In addition, two subunits $\mathrm{S} 1$ and $\mathrm{S} 2$, are found in the $\mathrm{S}$ protein molecule. Again, the ACE-2 receptor is linked to the S2 subunit and within this receptor, the S2 subunit forms fusion between the membrane of the host cell and the virus. As a result, the viral RNA can access the cytoplasm of the viral cell and replicate again [53]. Vaccine regarding $\mathrm{S}$ protein can also trigger antibodies that obstruct the binds of a viral receptor and even the uncoating of the viral genome in the cytoplasm. The $S$ proteinbased vaccine will play a major role in inducing protective immunity from SARS-CoV infection by neutralizing the $\mathrm{T}$ cell responses and triggering antibodies [53]. Based on the full-length genome phylogenetic study, SARS-CoV-2 has an almost $89 \%$ similarity with the SARS-CoV [54]. This was the foundation for the initial development of SARS-CoV-2 and indicated that the receptor of SARS-CoV-2 may be consistent with the receptor of SARS-CoV (ACE2) [55]. SARS-CoV-2 is reported to use angiotensin-converting enzyme 2 (ACE2) receptors to penetrate the target cells [56]. Therefore, any agent increasing ACE2 production may be anticipated to improve its susceptibility to intense COVID-19 by enhancing viral cellular invasion. However, biochemically, Angiotensin II is converted to angiotensin (1-7), defending lung damage by reducing the ACE2 receptor and vasodilation [57]. The patients with COVID-19 and co-morbidities such as hypertension, cardiovascular disorder, and diabetes that often have angiotensin-converting enzyme inhibitors ACEIs or angiotensin receptor blockers ARBs, there is often contradictory evidence about continuity or discontinuation of medications inhibiting the renin-angiotensin aldosterone system (RAAS), including inhibitors of angiotensin-converting enzyme (ACEIs) and angiotensin receptor blockers (ARBs) [58]. 5REB [59], 7BQY [60], and $6 \mathrm{Y} 2 \mathrm{~F}$ [61] have been previously denoted as main protease (Mpro) of SARS-CoV-2, and 6VW1 [62] and 1R42 [63] have been denoted as human angiotensinconverting enzyme 2 (ACE2). Taking all these considerations into account, five proteins $(5 \mathrm{REB}, 7 \mathrm{BQY}, 6 \mathrm{Y} 2 \mathrm{~F}$, $6 \mathrm{VW} 1,1 \mathrm{R} 42)$ have been selected to comply with the binding interactions between proteins and ligands.

\section{Pass prediction}

Caffeine, theaflavin, achyranthine, betaine, catechin, kaempferol, limonene, sabinene, piperine, pinene, favipiravir, and hydroxychloroquine were allowed to predict the antiviral activity by using the PASS online server [64]. PASS online server predicts the activity as probable of activity $(\mathrm{Pa})$ and probable inactivity $(\mathrm{Pi})$.

\section{Molecular analysis: compounds and target proteins}

Three-dimensional structures of the main protease in complex (hydrolase receptor) (PDB: 5REB) [65], the structure of SARS-CoV-2 chimeric receptor-binding domain complexed with its human receptor ACE2 (PDB: 6VW1) [66], native human angiotensin-converting enzyme-related carboxypeptidase (ACE2) (PDB: 1R42) 


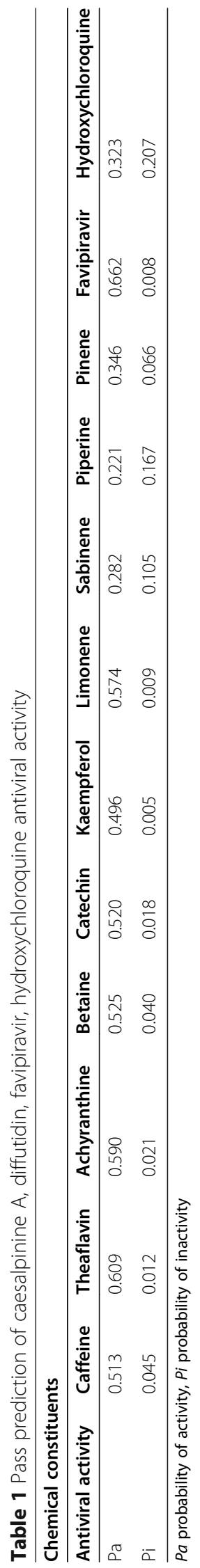


[67], the crystal structure of the COVID-19 main protease (PDB: 7BQY) [68], and crystal structure (monoclinic form) of the COVID-19 main protease were downloaded in PDB format. Besides, the chemical compounds have been selected based on the bioactive dietary compounds and synthetic compounds (caffeine, theaflavin, achyranthine, betaine, catechin, kaempferol, limonene, sabinene, piperine, pinene, favipiravir, and hydroxychloroquine) including antiviral properties. The compounds have been derived from the PubChem database (https://pubchem.ncbi.nlm. nih.gov/) [69] in SDF format.

\section{Molecular analysis: preparation of target protein and compounds}

The ligands have been imported in 2DSDF format; hereafter, the ligands have been minimized and converted to pdbqt format across the PyRx tools to find the best hit in these targets. The protein structure was created with Discovery Studio and UCSF Chimera. Default settings in the PyRx from the MGL tools [70] have been used for the virtual screening. Through the Discovery Studio 2020, all water and the heteroatom were eliminated from proteins. A combination of non-polar hydrogen and the Gasteiger charge was used to assemble proteins. Besides, extra solvents were deleted, selenomethionine (MSE), methionine (MET), bromo UMP to $\mathrm{UMP}(\mathrm{U})$, methylselenyl-dUMP (UMS), to UMP (U), methylselenyl-dCMP (CSL) to CMP (C) have been marked to keep only highest occupancy. Again, the incomplete side chains were replaced by Dunbrack 2010 rotomer library. Furthermore, all proteins have been lowered to the least energy level by keeping the residues in AMBER ff14sB and Gasteiger mode in UCSF Chimera [71].

\section{Molecular analysis: molecular docking}

For the protein-ligand binding operation of the selected protein-ligand complexes, PyRx Autodock Vina was used [26]. A semi-flexible docking system has been applied to perform the docking research. A semi-flexible docking system has been applied to perform the docking research. The phytochemicals were translated into PDBQT formats with PyRx AutoDock tools. The rigidity of proteins and ligands was retained for this analysis. Ligand molecules had given the freedom for 10 degrees. AutoDock determines the molecules to format pdbqt, box style, grid box formation, etc. The grid box with an active position was built in the middle of the box. BIOVIA Discovery Studio Visualizer 2020 [72] was eventually accelerated to evaluate the docking sites for the possible linking approaches.

\section{Determination of pharmacokinetic parameters by Swiss ADME}

Lipinski's rule evaluates the different descriptors which are important for drug design. According to Lipinski's rule, an orally active drug should fulfill the following drug-likeness parameters to demonstrate their pharmaceutical fidelity such as (i) molecular mass less than 500 Daltons, (ii) no more than $5 \mathrm{H}$-bond donors, (iii) no more than $10 \mathrm{H}$-bond acceptors, and (iv) $\mathrm{O} / \mathrm{W}$ partition coefficient $\log \mathrm{P}$ not greater than 5 . If the molecule violates more than 3 descriptor parameters, it will not fit into the criteria of drug likeliness, and it is not considered to proceed with drug discovery.

\section{Results}

Pass prediction of selected ligands

The results of the PASS prediction have been presented in Table 1. The study revealed that, among the four compounds, favipiravir and theaflavin retained the highest drug probability $\mathrm{Pa}(0.662$ and 0.609$)$.

\section{Molecular docking study for SARS-CoV-2 inhibition}

In the case of the antiviral docking study, the selected compounds were docked against the SARS-CoV-2's main protease (PDB: 5REB, 7BQY, 6Y2F), and angiotensinconverting enzyme 2 (PDB: 6VW1, 1R42) enzymes and displayed docking scores ranging from -3.2 to $-9.8(\mathrm{kcal} /$ $\mathrm{mol})$. The docking score and the best interaction figure have been shown in Table 2 and Fig. 3. From the findings, it was observed that the compound theaflavin exposed the highest score against PDB ID: 5REB, 6VW1, and 1R42, followed by kaempferol attained the highest binding affinity with the pockets of the main protease enzyme (Mpro) (7BQY and 6Y2F). The ranking of docking score for antiviral (SARS-CoV-2) effect against PDB ID: 5REB is as follows: theaflavin $>$ kaempferol $>$ favipiravir > hydroxychloroquine $>$ caffeine $>$ limonene $>$ sabinene $>$ achyranthine $>$ betaine. Docking observed docking score

Table 2 Docking score of the selected dietary bioactive and synthetic compounds

\begin{tabular}{llllll}
\hline Compounds & \multicolumn{7}{l}{ Docking score } & & & \\
\cline { 2 - 6 } & 5REB & $\mathbf{6 V W 1}$ & $\mathbf{1 R 4 2}$ & $\mathbf{7 B Q Y}$ & $\mathbf{6 Y 2 F}$ \\
\hline Caffeine & -5.1 & -4.8 & -5.7 & - & -5.0 \\
Theaflavin & $-\mathbf{6 . 3}$ & $-\mathbf{9 . 8}$ & $-\mathbf{8 . 6}$ & -6.7 & -6.4 \\
Achyranthine & -4.4 & -4.1 & -4.0 & -4.2 & -4.7 \\
Betaine & -3.5 & -3.2 & -3.2 & -3.4 & -3.5 \\
Catechin & - & -6.7 & -6.9 & -7.0 & -6.5 \\
Kaempferol & -6.2 & -7.0 & -6.8 & $-\mathbf{7 . 1}$ & $-\mathbf{6 . 6}$ \\
Limonene & -4.6 & -4.8 & -4.7 & -4.4 & -5.2 \\
Sabinene & -4.5 & -4.5 & -4.8 & -4.1 & -4.7 \\
Piperine & - & -6.8 & -7.0 & -6.5 & -7.1 \\
Pinene & - & -4.5 & -4.5 & -4.4 & -4.6 \\
Favipiravir & -5.4 & -4.7 & -5.2 & -5.5 & -5.3 \\
Hydroxychloroquine & -5.4 & -5.6 & -5.8 & -5.7 & -6.0 \\
\hline
\end{tabular}



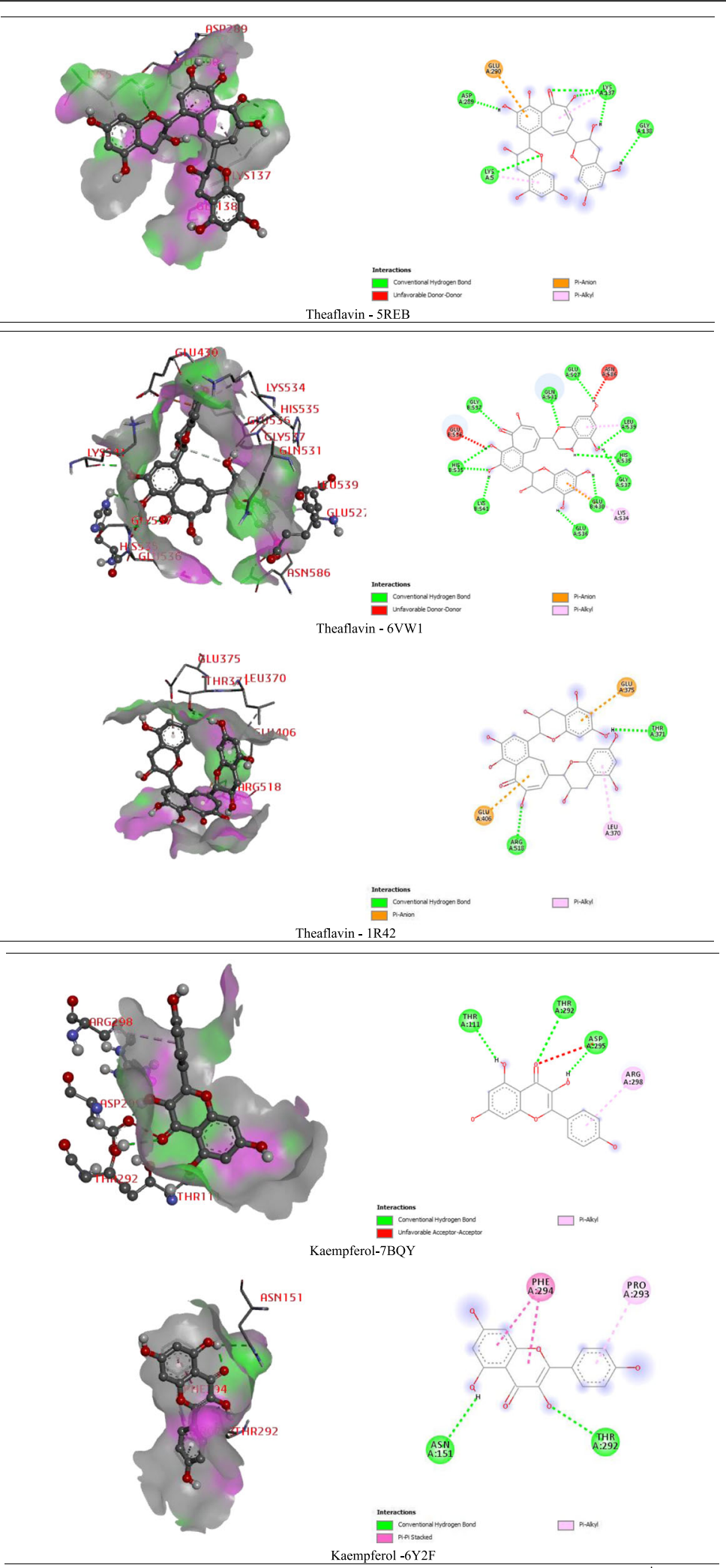

Fig. 3 The presentation of the best binding interactions of the selected bioactive dietary components and synthetic compounds with the five SARS-CoV-2 proteins (main protease and angiotensin-converting enzyme 2 receptors) 
Table 3 Absorption, distribution, metabolism, excretion, and toxicological properties of the selected compounds

\begin{tabular}{lllllllc}
\hline Compounds & Molecular Weight $(\mathbf{M} . \mathbf{W}) \mathbf{( g / m o l )}$ & HBD & HBA & log P (o/w) & HIA & Carcinogenicity (binary) & Violation score \\
\hline Caffeine & 194.19 & 0 & 6 & -1.03 & 0.9824 & 0.9429 & 0 \\
Theaflavin & 564.50 & 12 & 9 & 2.21 & 0.9836 & 0.9571 & 3 \\
Achyranthine & 129.16 & 1 & 2 & 0.02 & 0.9021 & 0.9571 & 0 \\
Betaine & 117.15 & 0 & 2 & -1.56 & 0.9333 & 0.7316 & 0 \\
Catechin & 290.27 & 5 & 6 & 1.55 & 0.9887 & 0.9286 & 0 \\
Kaempferol & 286.24 & 4 & 6 & 2.28 & 0.9881 & 0.6985 & 0 \\
Limonene & 136.24 & 0 & 0 & 3.31 & 0.9692 & 0.5856 & 0 \\
Sabinene & 136.24 & 0 & 0 & 3.00 & 0.9828 & 0.7286 & 0 \\
Piperine & 285.34 & 0 & 3 & 3.00 & 0.9639 & 0.9198 & 0 \\
Pinene & 136.24 & 0 & 0 & 3.14 & 0.9677 & 0.7286 & 0 \\
Favipiravir & 157.10 & 2 & 3 & -0.99 & 0.9612 & 0.9286 & 0 \\
Hydroxychloroquine & 335.88 & 2 & 4 & 3.78 & 0.9934 & 0.8429 & 0 \\
\hline
\end{tabular}

$H B D$ hydrogen bond donor, HBA hydrogen bond acceptor, LogP lipophilicity, HIA human intestinal absorption

and with the selected components and PDB ID: 6VW1 receptor, the scores were observed: theaflavin $(-9.8 \mathrm{kcal} /$ $\mathrm{mol})$, kaempferol $(7.0 \mathrm{kcal} / \mathrm{mol})$, piperine $(-6.8 \mathrm{kcal} / \mathrm{mol})$, catechin $(-6.7 \mathrm{kcal} / \mathrm{mol})$, hydroxychloroquine $(5.4 \mathrm{kcal} /$ $\mathrm{mol})$, limonene $(4.8 \mathrm{kcal} / \mathrm{mol})$, caffeine $(4.8 \mathrm{kcal} / \mathrm{mol})$, favipiravir $(-4.7 \mathrm{kcal} / \mathrm{mol})$, sabinene $(4.5 \mathrm{kcal} / \mathrm{mol})$, pinene $(4.5 \mathrm{kcal} / \mathrm{mol})$, achyranthine $(4.1 \mathrm{kcal} / \mathrm{mol})$, and betaine $(3.2 \mathrm{kcal} / \mathrm{mol})$ and respectively. Theaflavin yields the highest docking score against the $1 \mathrm{R} 42$ receptor. Theaflavin binds to the pocket of the $1 \mathrm{R} 42$ receptor through a series of bonds: conventional hydrogen bond (arg518, thr371), Pi-anion (glu406, glu375), and Pi-alkyl (leu370). The order of docking score against PDB ID: 7BQY is as follows: kaempferol $>$ catechin $>$ theaflavin $>$ piperine $>$ hydroxychloroquine $>$ favipiravir $>$ limonene $>$ pinene $>$ achyranthine $>$ sabinene $>$ betaine. Caffeine does not conjugate and neither oriented any docking to this ACE2 receptor. Again, kaempferol also exerted the best docking score as well as the best binding affinity to the main protease enzyme (PDB: 6Y2F). Kaempferol obtained the highest binding score via interaction of the amino acid series (asn158, phe294, pro293, and thr292) of the protein.

\section{Pharmacokinetics (ADME) and toxicological properties prediction}

The study was performed to check the pharmacokinetics and the toxicological properties of the caffeine, achyranthine, betaine, catechin, kaempferol, limonene, sabinene, and sabinene, piperine, pinene, favipiravir, and hydroxychloroquine. The pharmacokinetics and the toxicological properties of the selected ligands for the antiviral (SAR-CoV-SAR) efficacy have been shown in Table 3. The study revealed no violation of Lipinski's five rules and the ligands does not contain carcinogens.

\section{Discussion}

Molecular docking and computer-aided drug design (CADD) are vital tools in structural molecular biology. This tool contributes to predicting the binding mode of active compounds against the targeted proteins [73]. Additionally, it is used to comprehend the possible molecular mechanism of actions of various pharmacological activities [74]. The molecular docking was also performed to correlate with our current research outcomes and better understand the molecular mechanism [72]. In this study, twelve bioactive and synthetic compounds were examined against five targeted receptors or enzymes. The ideal antiviral drug candidate should have low toxicity, appropriate pharmacokinetics, and preferably a large spectrum of activity. Many adjuvants failed to be clinically used due to the lack of one or more of these properties [75]. In this study, 10 bioactive dietary constituents have been selected owing to their wide availability with antiviral efficacy. Besides, favipiravir and hydroxychloroquine have been pronounced to antiviral efficacy in previous investigations, though the investigations were not successfully proven [76-79]. The search for effective inhibitors of 5REB, 6Y2F, 6VW1, 1R42, and $7 \mathrm{BQY}$ has been the focus of drug discovery efforts and has led to the identification of some promising leads (caffeine, theaflavin, achyranthine, betaine, catechin, kaempferol, limonene, sabinene, piperine, pinene, favipiravir, and hydroxychloroquine) have shown good inhibitory activity on selective enzymes. Theaflavin yielded highest binding score among all the selected compounds. It scored $-6.3,-9.8$, and $-8.6(\mathrm{kcal} / \mathrm{mol})$ upon it was docked with the 5REB, 6VW1, and 1R42 enzymes. Theaflavin binds to the pocket of 6VW1 receptor through a series of bonds: conventional hydrogen bond (lys541, his535, gly537, gln531, glu527, leu539, gly537, glu430, gly536), Pi-alkyl (lys534), unfavorable donor 
(glu536, asn526), and resulted best binding affinity among the selected compounds. Besides, kaemperol showed highest binding affinity to the rest of the receptors (Fig. 3 and Table 2).

Favipiravir is one of the antiviral drugs tested against several SARS-CoV-2 envelope proteins [80]. Favipiravir, a pyrazine carboxamide derivative molecule, works as an antiviral molecule that is a prodrug against RNA viruses. This antiviral activity is attenuated by the competitive nature of favipiravir with purine nucleoside rather than pyrimidine nucleosides. Madin Darby Canine Kidney (MDCK) cell treated with favipiravir during in vitro assay provided favipiravir ribofuranosyl-5' - triphosphate (favipiravir-RTP), favipiravir ribofuranose (favipiravir-R), and favipiravir ribofuranosyl-5' -monophosphate (favipiravir-RMP) in HPLC analysis as metabolites among which chemically synthesized favipiravir-RTP showed positive outcome to inhibit the viral RNA polymerase activity in concentrations ranging from nanomolar to micromolar. This assay infers the projection that favipiravir, a prodrug, emits the antiviral property when it is intra-cellularly phosphoribosylated to be an active form, favipiravir-RTP to halt RNA polymerase. When a single molecule of favipiravir-RTP is efficiently incorporated into a nascent RNA strand, a partial inhibition of extension in viral RNA is observed and when double incorporation takes place, complete inhibition results in [81].

Despite not being an elucidated absolute mechanism of action of hydroxychloroquine against coronavirus, several mechanisms to elucidate its antiviral property are already proposed. Being a weekly basic drug, hydroxychloroquine upraises the $\mathrm{pH}$ within cells and at the cellular membrane, consequently inhibiting the virus's ability to fuse onto the cell membrane and enter host cells. Another proposed hydroxychloroquine mechanism includes inhibition of DNA and RNA synthesis along with immunomodulating and anti-inflammatory effects [82]. Hydroxychloroquine also infers the constraint of glycosylation of viral proteins, virus assembly, new virus particle transport, virus release, and other processes to achieve its antiviral effects [83]. Docking studies indicated that the binding interaction of selected bioactive and synthetic constituents with 5REB, 6Y2F, 6VW1, $1 \mathrm{R} 42$, and 7BQY had been concluded that the selected constituents might, in part, be responsible for the antiviral activity against SARS-CoV-2 through interactions with these target enzyme or receptor.

\section{Conclusions}

Theaflavin and kaempferol exert a high binding affinity to the pockets of SARS-CoV-2 proteins. Interaction of caffeine, theaflavin, achyranthine, betaine, catechin, kaempferol, limonene, sabinene, piperine, pinene, favipiravir, and hydroxychloroquine with main protease and angiotensin-converting enzyme 2 (ACE-2) proteins is ensured by molecular docking, which accredits the assertion of remarkable antiviral properties of these test moieties. Owing to design drugs for anti-COVID-19, this is just a primary investigation and further investigations are suggested to confirm the capacity of the ligands.

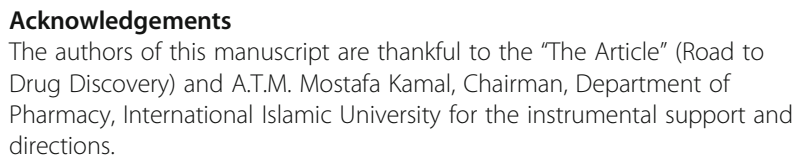

\section{Authors' contributions}

NUE: methodology, conceptualization; designing; investigation; formal analysis; software; writing-original draft; review and editing; supervision. MMA: methodology; formal analysis. IA: formal analysis; visualization; writingoriginal draft. SA: formal analysis; software. AAS: data curation; validation. MI: data curation; validation. MA: investigation. MHC: methodology. AM: writingoriginal draft. SH: writing-original draft. The authors read and approved the final manuscript.

\section{Funding}

This research does not obtain any grant or funding from any individuals or organizations.

\section{Availability of data and materials}

Data and material are available upon request.

\section{Declarations}

Ethics approval and consent to participate

The ethical consideration for this study is not applicable

\section{Consent for publication}

Not consent to publish.

\section{Competing interests}

The authors declare that they have no known competing interests or personal relationships that could have appeared to influence the work reported in this paper.

Received: 22 February 2021 Accepted: 7 June 2021

Published online: 15 June 2021

\section{References}

1. Organization, W. H (2020) Director-General's remarks at the media briefing on 2019-nCoVon 11 February 2020, Internet. World Health Organization.

2. Chen N, Zhou M, Dong X, Qu J, Gong F, Han Y, Qiu Y, Wang J, Liu Y, Wei Y (2020) Epidemiological and clinical characteristics of 99 cases of 2019 novel coronavirus pneumonia in Wuhan, China: a descriptive study. Lancet 395: 507-513

3. Organization, W. H (2020). Novel coronavirus (2019-nCoV): situation report, 3.

4. Shereen MA, Khan S, Kazmi A, Bashir N, Siddique R (2020) COVID-19 infection: origin, transmission, and characteristics of human coronaviruses. J Adv Res 24:91-98. https://doi.org/10.1016/j.jare.2020.03.005

5. Cascella M, Rajnik M, Cuomo A, Dulebohn SC, Di Napoli R (2020) Features, evaluation and treatment coronavirus (COVID-19). In StatPearls Internet., StatPearls Publishing

6. Wrapp D, Wang N, Corbett KS, Goldsmith JA, Hsieh C-L, Abiona O, Graham BS, McLellan JS (2020) Cryo-EM structure of the 2019-nCoV spike in the prefusion conformation. Science 367(6483):1260-1263. https://doi.org/10.112 6/science.abb2507

7. Hoffmann M, Kleine-Weber H, Schroeder S, Krüger N, Herrler T, Erichsen S, Schiergens TS, Herrler G, Wu N-H, Nitsche A (2020) SARS-CoV-2 cell entry depends on ACE2 and TMPRSS2 and is blocked by a clinically proven protease inhibitor. Cell. 181(2):271-280.e8. https://doi.org/10.1016/j.cell.2020. 02.052 
8. Rodríguez-Morales AJ, MacGregor K, Kanagarajah S, Patel D, Schlagenhauf P (2020) Going global-travel and the 2019 novel coronavirus. Travel Med Infect Dis 33:101578

9. Yang H, Bartlam M, Rao Z (2006) Drug design targeting the main protease, the Achilles' heel of coronaviruses. Curr Pharm Des 12(35):4573-4590. https://doi.org/10.2174/138161206779010369

10. Anand K, Ziebuhr J, Wadhwani P, Mesters JR, Hilgenfeld R (2003) Coronavirus main proteinase (3CLpro) structure: basis for design of antiSARS drugs. Science 300(5626):1763-1767. https://doi.org/10.1126/science.1 085658

11. Biondi-Zoccai G, Landoni G, Carnevale R, Cavarretta E, Sciarretta S, Frati G (2020) SARS-CoV-2 and COVID-19: facing the pandemic together as citizens and cardiovascular practitioners. Minerva Cardioangiol 68(2):61-64. https:// doi.org/10.23736/S0026-4725.20.05250-0

12. Kapetanovic I (2008) Computer-aided drug discovery and development (CADDD): in silico-chemico-biological approach. Chem Biol Interact 171(2): 165-176. https://doi.org/10.1016/j.cbi.2006.12.006

13. Emon NU, Alam MM, Uddin Sawon MS, Rana EH, Afroj M, Hasan Tanvir MM (2021) Biological and computational studies provide insights into Caesalphinia digyna Rottler stems. Biochemistry Biophys Rep 26:100994. https://doi.org/10.1016/j.bbrep.2021.100994

14. Emon NU, Alam S, Rudra S, Chowdhury S, Rajbangshi JC, Ganguly A (2020) Evaluation of pharmacological potentials of the aerial part of Achyranthes aspera L.: in vivo, in vitro and in silico approaches. In: Advances in traditional medicine

15. Friedman M (2007) Overview of antibacterial, antitoxin, antiviral, and antifungal activities of tea flavonoids and teas. Mol Nutr Food Res 51(1): 116-134. https://doi.org/10.1002/mnfr.200600173

16. Tait S, Salvati AL, Desideri N, Fiore L (2006) Antiviral activity of substituted homoisoflavonoids on enteroviruses. Antivir Res 72(3):252-255. https://doi. org/10.1016/j.antiviral.2006.07.003

17. Muhamad M, Kee LY, Rahman NA, Yusof R (2010) Antiviral actions of flavanoid-derived compounds on dengue virus type-2. Int J Biol Sci 6:294

18. Zu M, Yang F, Zhou W, Liu A, Du G, Zheng L (2012) In vitro anti-influenza virus and anti-inflammatory activities of theaflavin derivatives. Antivir Res 94(3):217-224. https://doi.org/10.1016/j.antiviral.2012.04.001

19. Chu N-S (1995) Sympathetic response to betel chewing. J Psychoactive Drugs 27(2):183-186. https://doi.org/10.1080/02791072.1995.10471690

20. Chatterjee A, Saluja M, Agarwal G, Alam M (2012) Green tea: a boon for periodontal and general health. J Indian Soc Periodontol 16(2):161-167. https://doi.org/10.4103/0972-124X.99256

21. Clark K, Grant P, Sarr A, Belakere J, Swaggerty C, Phillips T, Woode G (1998) An in vitro study of theaflavins extracted from black tea to neutralize bovine rotavirus and bovine coronavirus infections. Vet Microbiol 63(2-4): 147-157. https://doi.org/10.1016/S0378-1135(98)00242-9

22. Mhatre $S$, et al (2020) Antiviral activity of green tea and black tea polyphenols in prophylaxis and treatment of COVID-19: a review. Phytomedicine p. 153286

23. Akbar S (2020) Achyranthes aspera L.(Amaranthaceae). In: Handbook of 200 medicinal plants. Springer, Cham, pp 69-80

24. Goyal BR, Goyal RK, Mehta AA (2007) PHCOG REV.: plant review phytopharmacology of Achyranthes aspera: a review. Pharmacogn Rev 1(1)

25. Mukherjee H, Ojha D, Bag P, Chandel HS, Bhattacharyya S, Chatterjee TK, Mukherjee PK, Chakraborti S, Chattopadhyay D (2013) Anti-herpes virus activities of Achyranthes aspera: an Indian ethnomedicine, and its triterpene acid. Microbiol Res 168(4):238-244. https://doi.org/10.1016/j.micres.2012.11. 002

26. Emon NU, Alam S, Rudra S, Chowdhury S, Rajbangshi JC, Ganguly A (2020) Evaluation of pharmacological potentials of the aerial part of Achyranthes aspera L.: in vivo, in vitro and in silico approaches. In: Advances in traditional medicine, pp 1-14

27. Abhaykumar K (2018) Phytochemical studies on Achyranthes aspera. World Scientific News 100:16-34

28. Zhang M, Wu X, Lai F, Zhang X, Wu H, Min T (2016) Betaine inhibits hepatitis $B$ virus with an advantage of decreasing resistance to lamivudine and interferon a. J Agric Food Chem 64(20):4068-4077. https://doi.org/10.1 021/acs.jafc.6b01180

29. Evans W (1989) Trease and Evans Pharmacognosy Bailliere Tindall, London, pp 216-217

30. Peng W, Liu Y-J, Wu N, Sun T, He X-Y, Gao Y-X, Wu C-J (2015) Areca catechu L.(Arecaceae): a review of its traditional uses, botany, phytochemistry, pharmacology and toxicology. J Ethnopharmacol 164:340-356. https://doi org/10.1016/j.jep.2015.02.010

31. Shen D, Wu Q, Wang M, Yang Y, Lavoie EJ, Simon JE (2006) Determination of the predominant catechins in Acacia catechu by liquid chromatography/ electrospray ionization - mass spectrometry. J Agric Food Chem 54(9):3219_ 3224. https://doi.org/10.1021/jf0531499

32. Hsouna AB, Halima NB, Smaoui S, Hamdi N (2017) Citrus lemon essential oil: chemical composition, antioxidant and antimicrobial activities with its preservative effect against listeria monocytogenes inoculated in minced beef meat. Lipids Health Dis 16:1-11

33. del Rio J, Fuster M, Gómez P, Porras I, Garcla-Lidón A, Ortuño A (2004) Citrus Limon: a source of flavonoids of pharmaceutical interest. Food Chem 84: 457-461

34. Kim J, Jayaprakasha GK, Uckoo RM, Patil BS (2012) Evaluation of chemopreventive and cytotoxic effect of lemon seed extracts on human breast cancer (MCF-7) cells. Food Chem Toxicol 50(2):423-430. https://doi. org/10.1016/j.fct.2011.10.057

35. Klimek-Szczykutowicz M, Szopa A, Ekiert H (2020) Citrus Limon (lemon) phenomenon-a review of the chemistry, pharmacological properties, applications in the modern pharmaceutical, food, and cosmetics industries, and biotechnological studies. Plants (Basel) 9(1):119. https://doi.org/10.3390/ plants9010119

36. Ahmad N, Fazal H, Abbasi BH, Faroog S, Ali M, Khan MA (2012) Biological role of Piper nigrum L. (black pepper): a review. Asian Pac J Trop Biomed 2(3):S1945-S1953. https://doi.org/10.1016/S2221-1691(12)60524-3

37. Swathy J, Mishra P, Thomas J, Mukherjee A, Chandrasekaran N (2018) Antimicrobial potency of high-energy emulsified black pepper oil nanoemulsion against aquaculture pathogen. Aquaculture 491:210-220

38. Vasavirama K, Upender M (2014) Piperine: a valuable alkaloid from piper species. Int J Pharm Pharm Sci 6:34-38

39. Sabina EP, Nasreen A, Vedi M, Rasool M (2013) Analgesic, antipyretic and ulcerogenic effects of piperine: an active ingredient of pepper. J Pharmaceut Sci Res 5:203

40. Park TS, Jeong NS (2016) Piperine derivatives and uses thereof. Google Patents

41. Tiwari A, Mahadik KR, Gabhe SY (2020) Piperine: a comprehensive review of methods of isolation, purification, and biological properties. Med Drug Discov 7:100027. https://doi.org/10.1016/j.medidd.2020.100027

42. Silva ACR d, Lopes PM, Azevedo MMB d, Costa DCM, Alviano CS, Alviano DS (2012) Biological activities of a-pinene and $\beta$-pinene enantiomers. Molecules (Basel, Switzerland) 17:6305-6316

43. Shen C, et al (2020) Treatment of 5 critically ill patients with COVID-19 with convalescent plasma. Jama 323(16):1582-9

44. Zaraket H, Saito R (2016) Japanese surveillance systems and treatment for influenza. Curr Treatment Options Infect Dis 8(4):311-328. https://doi.org/1 0.1007/s40506-016-0085-5

45. Morgan Cooley FPSST (2016) Making a case for policy implications in research: a reflexive contemplation and call to action

46. Ziaie S, Koucheck M, Miri M, Salarian S, Shojaei S, Haghighi M, Sistanizad M (2020) Review of therapeutic agents for the treatment of COVID-19. J Cellular Mol Anesthesia 5:32-36

47. Gudadappanavar AM, Benni J (2020) An evidence-based systematic review on emerging therapeutic and preventive strategies to treat novel coronavirus (SARS-CoV-2) during an outbreak scenario. J Basic Clin Physiol Pharmacol 31(6). https://doi.org/10.1515/jbcpp-2020-0113

48. Lane, J. C., Weaves, J., Kostka, K., Alser, O., Prats-Uribe, A., Newby, D., and Prieto-Alhambra, D. (2020) Safety of hydroxychloroquine, alone and in combination with azithromycin, in light of rapid wide-spread use for COVID-19: a multinational, network cohort and self-controlled case series study, MedRXiv.

49. Gabriels J, Saleh M, Chang D, Epstein LM (2020) Inpatient use of mobile continuous telemetry for COVID-19 patients treated with hydroxychloroquine and azithromycin. HeartRhythm Case Reports 6(5):241243. https://doi.org/10.1016/j.hrcr.2020.03.017

50. Jin Z, Du X, Xu Y, Deng Y, Liu M, Zhao Y, Zhang B, Li X, Zhang L, Peng C (2020) Structure of M pro from SARS-CoV-2 and discovery of its inhibitors. Nature 582(7811):289-293. https://doi.org/10.1038/s41586-020-2223-y

51. Zhang L, Lin D, Sun X, Curth U, Drosten C, Sauerhering L, Becker S, Rox K Hilgenfeld R (2020) Crystal structure of SARS-CoV-2 main protease provides a basis for design of improved a-ketoamide inhibitors. Science 368(6489): 409-412. https://doi.org/10.1126/science.abb3405 
52. Gimeno A, Mestres-Truyol J, Ojeda-Montes MJ, Macip G, Saldivar-Espinoza B, Cereto-Massagué A, Pujadas G, Garcia-Vallvé S (2020) Prediction of novel inhibitors of the main protease (M-pro) of SARS-CoV-2 through consensus docking and drug reposition. Int J Mol Sci 21(11):3793. https://doi.org/10.33 90/ijms21113793

53. Du L, He Y, Zhou Y, Liu S, Zheng B-J, Jiang S (2009) The spike protein of SARS-CoV - a target for vaccine and therapeutic development. Nat Rev Microbiol 7(3):226-236. https://doi.org/10.1038/nrmicro2090

54. Jiang S, Du L, Shi Z (2020) An emerging coronavirus causing pneumonia outbreak in Wuhan, China: calling for developing therapeutic and prophylactic strategies. Emerg Microbes Infect 9(1):275-277. https://doi. org/10.1080/22221751.2020.1723441

55. Veljkovic $V$, et al (2020) Use of the informational spectrum methodology for rapid biological analysis of the novel coronavirus 2019-nCoV: prediction of potential receptor, natural reservoir, tropism and therapeutic/vaccine target. F1000Res 9:52. https://doi.org/10.12688/f1000research.22149.4

56. Wang Q, Zhang Y, Wu L, Niu S, Song C, Zhang Z, Lu G, Qiao C, Hu Y, Yuen K-Y (2020) Structural and functional basis of SARS-CoV-2 entry by using human ACE2. Cell 181:894-904 e899

57. Kreutz R, Algharably EAE-H, Azizi M, Dobrowolski P, Guzik T, Januszewicz A, Persu A, Prejbisz A, Riemer TG, Wang J-G (2020) Hypertension, the reninangiotensin system, and the risk of lower respiratory tract infections and lung injury: implications for COVID-19: European Society of Hypertension COVID-19 task force review of evidence. Cardiovasc Res 116(10):1688-1699. https://doi.org/10.1093/cvr/cvaa097

58. Vaduganathan M, Vardeny O, Michel T, McMurray JJ, Pfeffer MA, Solomon SD (2020) Renin-angiotensin-aldosterone system inhibitors in patients with Covid-19. N Engl J Med 382(17):1653-1659. https://doi.org/10.1056/NEJMsr2 005760

59. Fernandes MS, et al (2021) Insights on 3D structures of potential drugtargeting proteins of SARS-CoV-2: application of cavity search and molecular docking. Mol Informat 40(2):2000096

60. Alsafi MA, Hughes DL, Said MA (2020) First COVID-19 molecular docking with a chalcone-based compound: synthesis, single-crystal structure and Hirshfeld surface analysis study. Acta Crystallogr C Struct Chem 76(Pt 12): 1043-1050. https://doi.org/10.1107/S2053229620014217

61. Wlodawer A, Dauter Z, Shabalin IG, Gilski M, Brzezinski D, Kowiel M, Minor W, Rupp B, Jaskolski M (2020) Ligand-centered assessment of SARS-CoV-2 drug target models in the protein data Bank. FEBS J 287(17):3703-3718. https://doi.org/10.1111/febs.15366

62. Mohammadi S, Heidarizadeh M, Entesari M, Esmailpour A, Esmailpour M, Moradi R, Sakhaee N, Doustkhah E (2020) In silico investigation on the inhibiting role of nicotine/caffeine by blocking the S protein of SARS-CoV-2 versus ACE2 receptor. Microorganisms 8(10):1600. https://doi.org/10.3390/ microorganisms 8101600

63. Hussain M, Jabeen N, Raza F, Shabbir S, Baig AA, Amanullah A, Aziz B (2020) Structural variations in human ACE2 may influence its binding with SARS-CoV2 spike protein. J Med Virol 92(9):1580-1586. https://doi.org/10.1002/jmv.25832

64. Filimonov D, Lagunin A, Gloriozova T, Rudik A, Druzhilovskii D, Pogodin P, Poroikov V (2014) Prediction of the biological activity spectra of organic compounds using the PASS online web resource. Chem Heterocycl Compd 50(3):444-457. https://doi.org/10.1007/s10593-014-1496-1

65. Chan H, Pearson S, Green CM, Li Z, Zhang J, Lippard S, Belfort G, Shekhtman A, Li HM, Belfort M (2020) RecA mini intein-Zeise's salt complex.

66. Shang J, Ye G, Shi K, Wan Y, Luo C, Aihara H, Geng Q, Auerbach A, Li F (2020) Structural basis of receptor recognition by SARS-CoV-2. Nature 581(7807):221-224. https://doi.org/10.1038/s41586-020-2179-y

67. Towler P, Staker B, Prasad SG, Menon S, Tang J, Parsons T, Ryan D, Fisher M, Williams D, Dales NA, Patane MA, Pantoliano MW (2004) ACE2 X-ray structures reveal a large hinge-bending motion important for inhibitor binding and catalysis. J Biol Chem 279(17):17996-18007. https://doi.org/10.1 074/jbc.M311191200

68. Jin Z, Du X, Xu Y, Deng Y, Liu M, Zhao Y, Zhang B, Li X, Zhang L, Peng C, Duan Y, Yu J, Wang L, Yang K, Liu F, Jiang $R$, Yang $X$, You T, Liu X, Yang $X$, Bai F, Liu H, Liu X, Guddat LW, Xu W, Xiao G, Qin C, Shi Z, Jiang H, Rao Z, Yang $H$ (2020) Structure of M(pro) from SARS-CoV-2 and discovery of its inhibitors. Nature 582(7811):289-293. https://doi.org/10.1038/s41586-02 0-2223-y

69. Wang Y, Zhang S, Li F, Zhou Y, Zhang Y, Wang Z, Zhang R, Zhu J, Ren Y, Tan Y (2020) Therapeutic target database 2020: enriched resource for facilitating research and early development of targeted therapeutics. Nucleic Acids Res 48(D1):D1031-D1041. https://doi.org/10.1093/nar/gkz981

70. Herowati R, Widodo GP (2014) Molecular docking studies of chemical constituents of Tinospora cordifolia on glycogen phosphorylase. Procedia Chemistry 13:63-68. https://doi.org/10.1016/j.proche.2014.12.007

71. Beglov D, Hall DR, Brenke R, Shapovalov MV, Dunbrack RL Jr, Kozakov D, Vajda S (2012) Minimal ensembles of side chain conformers for modeling protein-protein interactions. Proteins Structure Function Bioinformatics 80(2):591-601. https://doi.org/10.1002/prot.23222

72. Emon NU, et al (2021) Antidepressant, anxiolytic, antipyretic, and thrombolytic profiling of methanol extract of the aerial part of Piper nigrum: In vivo, in vitro, and in silico approaches. Food Sci Nutr 9(2):833-46

73. Khan S, Nazir M, Raiz N, Saleem M, Zengin G, Fazal G, Saleem H, Mukhtar M, Tousif MI, Tareen RB (2019) Phytochemical profiling, in vitro biological properties and in silico studies on Caragana ambigua stocks (Fabaceae): a comprehensive approach. Ind Crop Prod 131:117-124. https://doi.org/10.101 6/j.indcrop.2019.01.044

74. Alam S, Emon NU, Shahriar S, Richi FT, Haque MR, Islam MN, Sakib SA, Ganguly A (2020) Pharmacological and computer-aided studies provide new insights into Millettia peguensis Ali (Fabaceae). Saudi Pharmaceutical J 28(12):1777-1790. https://doi.org/10.1016/j.jsps.2020.11.004

75. Abdel-Halim H, Abdelhalim A, Abdelmalek S (2019) The search of potential inhibitors of the AcrAB-TolC system of multidrug-resistant Escherichia coli: an in silico approach. Appl Microbiol Biotechnol 103(15):6309-6318. https:// doi.org/10.1007/s00253-019-09954-1

76. Shrestha DB, Budhathoki P, Khadka S, Shah PB, Pokharel N, Rashmi P (2020) Favipiravir versus other antiviral or standard of care for COVID-19 treatment: a rapid systematic review and meta-analysis. Virol J 17:1-15

77. Coomes EA, Haghbayan H (2020) Favipiravir, an antiviral for COVID-19? J Antimicrob Chemother 75(7):2013-2014. https://doi.org/10.1093/jac/dkaa171

78. Fan J, et al (2020) Connecting hydroxychloroquine in vitro antiviral activity to in vivo concentration for prediction of antiviral effect: a critical step in treating COVID-19 patients. Clin Infect Dis

79. Molina JM, Delaugerre C, Le Goff J, Mela-Lima B, Ponscarme D, Goldwirt L, de Castro N (2020) No evidence of rapid antiviral clearance or clinical benefit with the combination of hydroxychloroquine and azithromycin in patients with severe COVID-19 infection. Med Mal Infect 50(4):384. https:// doi.org/10.1016/j.medmal.2020.03.006

80. Valle C, Martin B, Touret F, Shannon A, Canard B, Guillemot JC, Coutard B, Decroly E (2020) Drugs against SARS-CoV-2: what do we know about their mode of action? Rev Med Virol 30(6):1-10. https://doi.org/10.1002/rmv.2143

81. Furuta Y, Komeno T, Nakamura T (2017) Favipiravir (T-705), a broad spectrum inhibitor of viral RNA polymerase. Proc Jpn Acad Ser B Phys Biol Sci 93(7):449-463. https://doi.org/10.2183/pjab.93.027

82. Reilly J (2020) Treatment considerations for coronavirus (COVID-19). Hospital Pract 48(3):119-20

83. Vincent MJ, Bergeron E, Benjannet S, Erickson BR, Rollin PE, Ksiazek TG, Seidah NG, Nichol ST (2005) Chloroquine is a potent inhibitor of SARS coronavirus infection and spread. Virol J 2(1):69. https://doi.org/10.1186/1 $743-422 X-2-69$

\section{Publisher's Note}

Springer Nature remains neutral with regard to jurisdictional claims in published maps and institutional affiliations. 